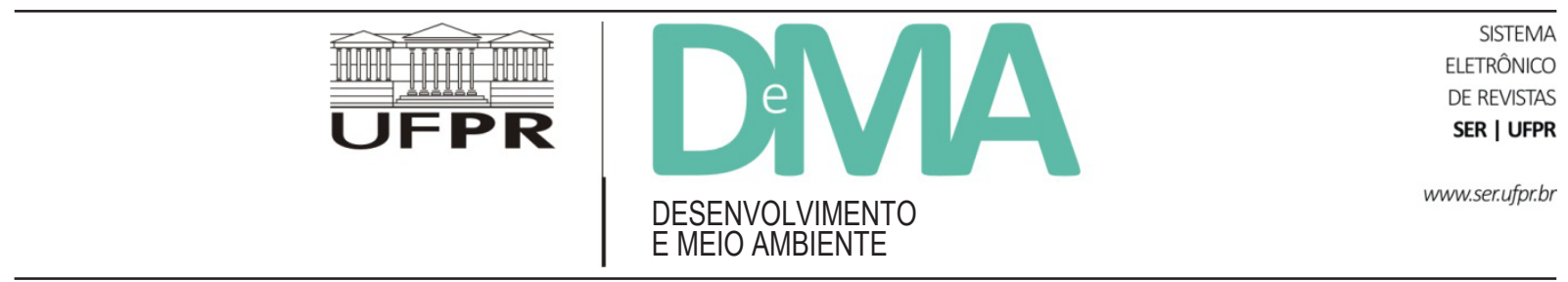

\title{
Extensão participativa para a sustentabilidade da pesca artesanal
}

\section{Participatory Extension to the Sustainability of Artisanal Fisheries}

\author{
Antônio Marcos Muniz CARNEIRO ${ }^{1 *}$, Antônio Carlos Sant'Ana DIEGUES ${ }^{2}$, Luiz Fernando Silva VIEIRA ${ }^{3}$ \\ ${ }^{1}$ Programa de Engenharia de Produção (COPPE), Universidade Federal do Rio de Janeiro (UFRJ), Rio de Janeiro, RJ, Brasil. \\ ${ }^{2}$ Programa de Pós-Graduação em Ciência Ambiental (PROCAM), Universidade de São Paulo (USP), São Paulo, SP, Brasil. \\ ${ }^{3}$ Área de Proteção Ambiental (APA) de Massambaba, Instituto Estadual do Ambiente (INEA), Rio de Janeiro, RJ, Brasil. \\ *E-mail de contato: carneiro@pep.ufrj.br
}

Artigo recebido em 02 de abril de 2014, versão final aceita em 28 de novembro de 2014.

RESUMO O presente artigo consiste em uma proposta metodológica de projeto de extensão pesqueira participativa, coordenado por uma equipe do Programa de Engenharia de Produção da COPPE/UFRJ com ênfase na Gestão de Recursos Naturais, para a sustentabilidade da pesca artesanal marinha em uma região litorânea da costa Sudeste do Brasil. Tal metodologia proposta é interativa e desenvolve-se recursivamente, configurando-se mediante um assessoramento dialógico. Ela pressupõe ser todo o problema de extensão complexo, tornando imprescindíveis abordagens interdisciplinares e interativas para que os processos de resoluções de problemas do setor da pesca artesanal possam ser realizados pelo compartilhamento de conhecimentos marítimos científicos e tradicionais. Nesse sentido, sua abordagem é alternativa à concepção linear e antidialógica de extensionismo no Brasil que fora denunciada por Paulo Freire em sua obra seminal “Comunicação ou Extensão?". Ela fundara a política de extensão pesqueira do governo brasileiro nas décadas de 60/70 do século passado cujos efeitos foram danosos aos ecossistemas costeiros, estuarinos e marinhos do país, afetando a produtividade deles e da própria pesca artesanal: rápida expansão urbana, crescimento desenfreado do turismo com desvalorização das culturas locais, localização de polos industriais, poluição, construção de estradas, falta de saneamento e outros. O objetivo deste artigo é disponibilizar um framework metodológico para projetos de extensão, apropriados à complexidade da pesca artesanal, caracterizada por intervenções multiespecíficas e associadas a padrões de regularidade dos ecossistemas marinhos cuja dinâmica possui alta incerteza com movimentos aleatórios e caóticos. Suas principais referências teóricas compreendem três perspectivas: (a) as implicações recíprocas entre teoria e prática da pesquisa-ação; (b) a essencialidade da comunicação e da linguagem nos instrumentos das metodologias participativas; (c) a gestão por processos em base comunitária de pescadores de pequena escala. Essas perspectivas, por sua vez, encontram-se fundamentadas teoricamente em dois campos de estudos interdisciplinares: a Etnociência e a Sociocognição.

Palavras-chave: pesca artesanal; conhecimentos ecológicos tradicionais; extensão pesqueira participativa; etnociência; sociocognição. 
ABSTRACT The present work consists in a methodological proposal for the fishing activity extension project. It will be coordinated by a Production Engineering Program team from COPPE/UFRJ, focusing on the Natural Resources Management for the sustainability of the marine artisanal fishing in a southeastern Brazil seaside region. Such proposed methodology is interactive and it is recursively developed, configuring it through a dialogic advice. This methodology assumes that the whole problem is of complex extension, making essentially the interdisciplinary and interaction approaches. Therewith, the resolution problems in the handmade fishery department may be performed by sharing scientific and traditional marine knowledge. In this way, the approach is an alternative to the linear and anti-dialogical conception, as it was denounced by Paulo Freire in his seminal work “Comunicação ou Extensão?" (Communication or Extension?), about the extension in Brazil. This methodology founded the Brazilian government fishery extension politics between the last century's sixties and seventies, whose outcome was harmful to the country coastal, estuarine and seafarers ecosystems, affecting their productivity and artisanal fishing itself: rapid urban expansion, rampant growth of tourism with the devaluation of the local cultures, location of industrial parks, pollution, construction of roads, lack of sanitation and others. The purpose of this article is to provide a methodological framework for extension projects that is appropriate to the complexity of artisanal fisheries, characterized by multi-species and associated patterns of regularity of marine ecosystems interventions whose dynamics is highly uncertain with random and chaotic movements. Its main theoretical references comprise three perspectives: (a) the reciprocal implications between theory and practice of action research, (b) the essential communication and language in the instruments of participatory methodologies, (c) management by processes in community-based of small-scale fishers. These perspectives, in turn, are theoretically grounded in two fields of interdisciplinary studies: Ethno-science and Socio-cognition.

Keywords: artisanal fishing; traditional ecological knowledge; participatory fisheries extension; ethno-science; socio-cognition.

\section{Introdução}

Este artigo consiste em uma proposta metodológica de Assistência Técnica e Extensão Pesqueira Participativa (ATEPP) $)^{1}$ para a sustentabilidade da pesca artesanal (ou de pequena escala) de povos tradicionais costeiros, alternativa, porém, à concepção linear e antidialógica do extensionismo, denunciada por Paulo Freire em sua obra seminal “Comunicação ou Extensão?”. Tal concepção fora orientadora da política de extensão pesqueira dos governos brasileiros nas décadas de 60/70 do século passado cujos efeitos impactaram dramaticamente as comunidades pesqueiras. Essas políticas, orientadas pela ideologia desenvolvimentista à época (Oliveira \& Silva, 2012) tiveram papel preponderante nos efeitos danosos aos ecossistemas costeiros, estuarinos e marinhos do país, afetando a produtividade deles e da própria pesca artesanal, conforme apontam Vasconcellos et al. (2007): rápida expansão urbana, crescimento desenfreado do turismo com desvalorização das culturas locais, localização de polos industriais, poluição, construção de estradas, falta de saneamento e outros.

A ATEPP aqui proposta reflete uma tendência internacional do extensionismo rural emergente nos anos 1990 de superação do modelo clássico de transferência de tecnologia por um novo paradigma constituído pelo diálogo e a participação, designado "participatory extension" (Brose, 2004). Nesse sentido, a sua concepção compartilha, também, de mudanças que passaram a valorizar a extensão universitária brasileira no terceiro milênio, modificando o seu clássico significado assistencialista de "repasse" de conhecimentos das várias áreas

\footnotetext{
${ }^{1}$ No Brasil, o termo "extensão", com o significado básico comum de "transferência" de conhecimentos, teve aplicações e finalidades distintas: a Assistência Técnica e Extensão Rural/ Pesqueira - ATER/ATEP para o desenvolvimento econômico da produção de bens primários no meio rural e a extensão universitária de sentido assistencialista.
} 
das ciências para grupos sociais carentes ou pobres da cidade e do campo em posições passivas de receptores para as noções de "interlocução", "diálogo" ou "troca de saberes" com grupos sociais em posições protagonistas (Thiollent et al., 2003; Carneiro, 2003).

Ainda em relação à extensão universitária, Thiollent et al. (2003) já haviam observado que o Plano Nacional de Educação - PNE lei no.10.172/2001, em sua referência à Educação Superior, introduziu formulações que poderiam contribuir para a aplicação do conhecimento e $\theta$ intercâmbio de saberes na relação universidade e sociedade. Alguns anos depois, a ocorrência do aumento no índice de trabalhos acadêmicos sobre conhecimentos ecológicos tradicionais, constatada por Diegues (2007), leva-nos a inferir alguma modificação ou tendência à superação da histórica desvalorização da extensão nas instituições de ensino superior do Brasil, no sentido de ações contextualizadas na sociedade brasileira, principalmente, junto aos povos tradicionais da pesca artesanal no litoral brasileiro devido às suas maiores vulnerabilidades.

A exposição da proposta metodológica é precedida de uma abordagem panorâmica dos serviços públicos de (ATEP) desde sua criação até hoje, prestados pelo Governo Federal à pesca artesanal, destacando a caracterização desta atividade de pequena escala na atualidade, a crise do setor provocada pelo modelo clássico de extensão e encerrando com as tendências e desafios tanto políticos quanto científicos para a ATEP. No item subsequente, é apresentado o framework de uma metodologia interativa, "Extensão Participativa da Pesca Artesanal em Contexto", constituído pelos seguintes tópicos: (a) Conhecimentos marítimos tradicionais $e$ cientificos: estruturação e dinâmica (b) Pesquisa-ação participativa: interatividade e recursividade. Por fim, é apresentado um estudo de caso referente à utilização da metodologia proposta em um projeto de extensão universitária voltado para a sustentabilidade da pesca artesanal em uma região costeira do Sudeste brasileiro.

\section{A Assistência Técnica e Extensão da Pesca Artesanal no Brasil: caracterização, crise e tendências}

\subsection{A pesca artesanal hoje: caracterização e importância}

Apesar da falta de uma definição universal, a pesca artesanal pode ser amplamente reconhecida na atualidade por algumas de suas características mais comuns: manejo comunitário dos recursos pesqueiros com base em conhecimentos tradicionais dos ecossistemas marinhos e costeiros, captura multiespecífica de espécies-alvo (peixes, crustáceos, moluscos, algas) em águas rasas (praias, baías, lagunas, lagoas, estuários, ilhas), baixa autonomia de navegação com proximidade da linha da costa e produção econômica de subsistência para a reprodução social dos pescadores artesanais. Em razão da adaptabilidade de seu manejo à biodiversidade e à dinâmica ecossistêmica, as artes de pesca (apetrechos e manejo) são extremamente diversificadas com base em "conhecimentos ecológicos tradicionais" (CET), compartilhados entre gerações através de séculos, gerados nas interações de pescadores com as pescarias (Berkes et al., 2001; Diegues, 2007; Carneiro, 2013).

A autonomia e a propriedade de meios próprios de produção são consideradas, também, na definição da atividade pela Política Nacional de Desenvolvimento Sustentável da Aquicultura e da Pesca - Lei de Pesca 11.959/2009. Como se pode deduzir, a pesca artesanal é, em geral, uma atividade de baixo impacto ambiental por ser constituída de relações simbióticas com o mar, tornando-a vulnerável às ameaças de mudanças ecossistêmicas de causas antropogênicas (efeito estufa, degradação costeira, poluição etc.). O sucesso das capturas multiespecíficas depende das interações ecossistêmicas que assegurem os ciclos reprodutivos e sazonais das populações de fauna e flora aquáticas.

Dados da FAO (2012) sobre a produção mundial da pesca permitem deduzir a importância socioeconômica desta atividade. A pesca artesanal emprega mais de $90 \%$ do total estimado em 53 milhões pescadores e aquicultores no mundo e é de grande importância como 
a melhor fonte de proteína animal para a segurança alimentar de cerca de 357 milhões de pessoas. Além disso, ela é responsável por aproximadamente $50 \%$ do total de 154 milhões de toneladas da produção mundial de pescado, ao lado da pesca industrial e da aquicultura. E no Brasil, a pesca artesanal também se destaca, tendo sido responsável por mais da metade da produção pesqueira nacional, superando a pesca industrial e a aquicultura: $51,4 \%$ de 1.009.073 milhão/toneladas da produção pesqueira nacional em 2005, acima da pesca industrial e da aquicultura (IBAMA/MMA, 2005).

Além de sua notória importância para a segurança alimentar nos países das economias periféricas, a pesca artesanal ou de pequena escala tem sucesso e dinamismo nos países de economias centrais como os EUA e o Canadá (Berkes et al., 2001). Na Europa, a Noruega, país nórdico com forte tradição pesqueira no Atlântico Norte e o primeiro lugar no ranking dos indicadores de qualidade de vida e sustentabilidade, os pescadores artesanais não se proletarizaram e mantiveram a coexistência do setor com a pesca industrial (Diegues, 1983). Na Ásia, o Japão, situado entre as cinco principais economias mundiais e referência da terceira revolução industrial de base microeletrônica, desenvolveu no sentido botton up um bem sucedido sistema nacional de cogerenciamento de base comunitária da pesca costeira e com os direitos consuetudinários de apropriação dos espaços marítimos pelas famílias tradicionais costeiras, assegurados pela Revolução dos Meiji, desde o final do século XIX (Yamamoto, 1995).

Estudos de avaliação econômica de serviços ecossistêmicos costeiros têm atribuído maior importância para a pesca do que para outros investimentos de grandes impactos antropogênicos. As zonas costeiras no mundo, regiões naturais dessa atividade, são estreitas faixas de transição entre o continente e o mar, onde se encontram os berçários da vida marinha, beneficiando, diretamente, a pesca artesanal ou de pequena escala e possuem alta relevância econômica. Com apenas $8 \%$ da superfície do Planeta Terra, elas detêm 43\% da média atual da produção dos serviços ecossistêmicos estimada em US\$ 14,19 trilhões, mais de 50\% do PIB mundial (Constanza et al.,1997). Segundo pesquisa que associou, proporcionalmente, capturas pesqueiras no oceano $\mathrm{Pa}$ cífico, na região do golfo da Califórnia, à quantidade de manguezais preservados, esses ecossistemas valem muito mais para a biodiversidade do que para a especulação imobiliária (Aburto-Oropeza et al., 2008). Os valores dos dividendos proporcionados pela pesca para cada hectare de manguezal equivalem a US\$ 40 mil por ano ou 600 vezes mais, aproximadamente, do que o valor dado a ele pelo governo mexicano. Também, na Tailândia, estudo revela que um hectare de manguezal preservado vale entre US\$ 1.000 a 36.000 , bem acima dos US\$200 para um hectare de manguezais convertidos em viveiros de camarões.

Porém, devido à sua configuração ecossistêmica, $\mathrm{o}$ sucesso ou fracasso da pesca artesanal no litoral, está diretamente associado às dinâmicas e mudanças dos ecossistemas costeiros e marinhos. No contexto de mudanças ecossistêmicas abruptas e não lineares, a crise da pesca em nível global está mais associada à erosão dos meios de vida das populações tradicionais do que somente ao decréscimo da abundância dos recursos pesqueiros, com a perda das diversidades biológicas e culturais, acarretando o seu empobrecimento e marginalização (MEA, 2005; Kalikoski, 2007). Um fator agravante é a redução das áreas de atuação da pesca artesanal com a criação de parques marinhos sob o modelo ainda dominante de conservação que pressupõe a separação da natureza a ser preservada das sociedades humanas (Diegues, 2000). Berkes et al. (2001) chamam a atenção para o paradoxo dessa crise que é o aumento progressivo da dependência humana dos recursos marinhos e costeiros ao mesmo tempo em que estes são ameaçados cada vez mais pelo crescimento da sobrepesca e da degradação dos habitats.

\subsection{Impactos e crise do modelo clássico da extensão}

Historicamente, a pesca artesanal no Brasil, assim como as demais atividades do setor primário realizadas por populações tradicionais, tem sofrido os efeitos de uma série de impactos de instituições em diversos níveis. Conforme estudo de Berkes (2005) sobre a importância da gestão realizada em diversos níveis na escala institucional, os efeitos da verticalização da gestão governamental dos recursos naturais, excessivamente centralizadora e baseada na ciência clássica moderna, tendem 
a solapar os sistemas de conhecimento e as instituições locais. Alguns estudos de historiografia (Pádua, 2004)² e de extensão (Lima et al., 2004) permitem-nos compreender que esses impactos sobre a pesca artesanal litorânea assim como sobre os ecossistemas marinho e costeiro dessa atividade, acarretando pobreza e degradação da biodiversidade, intensificados nas últimas décadas, têm origens na colonização e formação da nação brasileira cuja lógica extrativista predatória ao meio ambiente tropical e às culturas nativas se mantivera por políticas públicas do Estado brasileiro para o setor a partir do início do século XX. Isso implicou a expropriação da terra dos povos nativos, institucionalização das sesmarias e da escravidão, substituição da biodiversidade regional pela introdução de espécies exóticas e o manejo monoespecífico (ou da monocultura) com baixo conhecimento da natureza local (Lima et al., 2004; Pádua, 2004).

Essa origem colonial do Brasil propiciou o predomínio da lógica do desenvolvimento do setor pesqueiro nacional mediante a implantação de novas tecnologias de pesca já no início do século XX, quando a Marinha de Guerra criou as colônias de pescadores por meio da Missão do Cruzador "José Bonifácio" (1919-1924) como parte da estratégia de proteção militar da costa nacional e o desenvolvimento das indústrias da pesca no Brasil (Callou, 1994). A institucionalização dessas colônias no litoral brasileiro foi feita de modo vertical e autoritário, trazendo repercussões negativas para a legitimidade institucional dos pescadores, com representações alheias à categoria e grandes resistências para uma cultura de democracia participativa, dificultando a atuação deles como sujeitos ativos nos processos decisórios das políticas públicas para o desenvolvimento da pesca artesanal (Callou, 1994). Deve-se ressaltar, porém, que essa fragilidade institucional não é exclusiva desse setor produtivo, mas generalizada na maioria das instituições das categorias profissionais do Brasil (sindicatos, associações corporativas, cooperativas etc.), criadas pela ditadura do Estado Novo.

A partir da segunda metade do século XX, a pesca artesanal foi mais severamente impactada por políticas de modernização do Estado brasileiro ${ }^{3}$, por meio da promoção de processos desordenados de ocupação, urbanização e localização industrial, acarretando a degradação dos ecossistemas marinhos e costeiros. Articulado com essas políticas, o governo federal interveio nas comunidades tradicionais costeiras da pesca artesanal. Através da Superintendência de Desenvolvimento da Pesca - SUDEPE, fundada em 1962, ele institucionalizou o serviço de extensão pesqueira em 1968 com objetivo de melhorar a vida dos pescadores na perspectiva do difusionismo e lançou, nos anos 1970, o Programa de Apoio à Pesca Artesanal - PESCART, um serviço público de prestação de assistência técnica aos pescadores artesanais e às suas organizações para a solução de seus problemas socioeconômicos e a difusão de modernas tecnologias de pesca. Os argumentos utilizados para persuadir os pescadores eram a abundância de pescados na imensa costa brasileira e a situação de abandono e completo desamparo das comunidades pesqueiras artesanais (Callou, 1994; PNAE/SEAP, 2008).

Em consonância com a lógica capitalista, o Governo Federal acabou priorizando e beneficiando setor pesqueiro industrial através de incentivos fiscais, mantendo no abandono o setor da pesca artesanal, gerando a degradação ambiental, o empobrecimento, a diminuição drástica da produção e a consequente exclusão social das famílias das tradicionais comunidades da pesca artesanal com a baixa autoestima em relação à sua cultura, ao invés do desenvolvimento social e econômico

\footnotetext{
${ }^{2}$ Segundo este historiador, a consciência crítica da degradação ambiental e social em países como Brasil teria origens muito antes do que se convencionou considerar como um fenômeno contemporâneo, provocado pela expansão planetária da civilização urbano-industrial, como uma realidade recente do debate europeu e norte-americano. Segundo ele, há uma historiografia que vem retrocedendo em alguns séculos a cronologia da controvérsia ambiental no país, provocando alterações profundas nas origens e identidades da consciência ecológica na modernidade (Pádua, 2004).

${ }^{3}$ A modernização do meio rural brasileiro constituiu um processo de tecnificação que trouxe benefícios para os setores produtivos, mas gerou concentração de renda, exclusão social, desemprego e abandono do campo e na cidade. O resultado deste processo foi decorrente de "revoluções" nos setores primários de produção que substituíram de forma deliberada a diversidade biológica pela sua uniformidade e a policultura pela monocultura: Revolução Verde na agricultura, Revolução Branca nos laticínios e Revolução Azul na pesca (Brose, 2004).
} 
proposto (Diegues, 1983; Callou, 1994; PNAE/SEAP, 2008; Oliveira \& Silva, 2012). Os efeitos dessas políticas foram dramáticos e de grandes proporções sobre esses povos, principalmente por serem dependentes dos serviços ecossistêmicos e diferenciados culturalmente. Os resultados dessas políticas que não consideraram o rico patrimônio dos conhecimentos tradicionais dos pescadores artesanais sobre a biodiversidade dos ecossistemas aquáticos não chegaram a lograr êxito para a alteração da realidade pesqueira. As consequências dessas políticas foram extremamente danosas aos ecossistemas costeiros, estuarinos e marinhos, afetando a produtividade deles e da própria pesca artesanal: rápida expansão urbana, crescimento desenfreado do turismo com desvalorização das culturas locais, localização de polos industriais, poluição, construção de estradas, falta de saneamento e outros (PNAE/SEAP, 2008; Vasconcellos et al., 2007). E, com a extinção da SUDEPE, em 1989, e o crescimento das mudanças ecossistêmicas por causas antropogênicas no litoral, as fragilidades dos pescadores e de suas famílias foram agravadas com a falta dos serviços públicos de apoio ao setor pesqueiro.

\subsection{Tendências e desafios}

A extensão pesqueira no Brasil de caráter público, estagnada desde a extinção da SUDEPE no final da década de 1980, é retomada em 2003 com a criação da Secretaria Especial de Aquicultura e Pesca da Presidência da República (SEAP/PR), posteriormente transformada no Ministério da Pesca e Aquicultura em 2009. Com a criação destes novos órgãos específicos do Governo Federal para a pesca, novas políticas públicas foram apresentadas como alternativas ao modelo clássico de transferência de tecnologia e identificadas com o novo paradigma constituído pelo diálogo e a participação "participatory extension" (Brose, 2004), abrangendo as extensões pesqueira, rural e, também, universitária, a saber:

- Plano Nacional de Extensão Pesqueira e Aquícola (PNEPA) - SEAP/PR (2008), documento subsidiário para a consolidação de uma política nacional de extensão rural, com o objetivo geral de promover o desenvolvimento local sustentável e solidário, com vistas à inclusão social e melhoria da qualidade de vida das comunidades pesqueiras e aquícolas, com a valorização do seu patrimônio de conhecimentos tradicionais associados à biodiversidade marinha;

- Política Nacional de Assistência Técnica e Extensão Rural (PNATER) - Ministério do Desenvolvimento Agrário (2010), tendo como um de seus princípios a adoção de uma abordagem multidisciplinar e interdisciplinar, com a adoção de novos enfoques metodológicos participativos da extensão;

- Política Nacional de Extensão Universitária - Considerada como um instrumento de mudança social em direção à justiça, à solidariedade e à democracia, deliberada de forma ampla e participativa no âmbito do Fórum dos Pró-Reitores de Extensão das Universidades Públicas (FORPROEX), também, com a adoção de metodologias que proporcionem à sociedade o papel de interlocutora qualificada em suas interações com as universidades através das iniciativas de extensão.

Entretanto, apesar dessa retomada recente da extensão pesqueira no Brasil identificada com o novo paradigma participatory extension, a pesca artesanal continua a sofrer de problemas de décadas passadas, agravados com os efeitos excludentes da globalização econômica e degradantes das mudanças ecossistêmicas. Carvalho \& Callou (2008) constataram este quadro através da análise dos projetos de extensão pesqueira da SEAP/PR (2003-2006) no Estado de Pernambuco na perspectiva do desenvolvimento local (alto índice de analfabetismo; impactos ambientais pela expansão imobiliária, aceleramento dos aterros de mangues; pesca predatória; incipiente assistência técnica e extensão pesqueira pública etc.). Outros instrumentos de gestão pública do litoral brasileiro continuam praticamente pouco eficientes, tornando mais vulneráveis os seus ecossistemas. A centralização do Estado brasileiro e a falta de participação das sociedades locais têm sido os principais entraves à implementação do Plano Nacional do Gerenciamento Costeiro (PNGC) instituído pela Lei no. 7.661 em 1988 (Pollette et al., 2006) e das Reservas Extrativistas Marinhas (RESEX Marinhas), que 
continuam sem os seus planos de manejo participativos (Carneiro \& Vieira, 2013.) ${ }^{4}$.

No caso da gestão da pesca artesanal, as referências teórico-metodológicas continuam sendo insuficientes para se compreender e evitar fracassos no desenvolvimento de estratégias pesqueiras sustentáveis. Conforme o consenso entre diferentes pesquisadores (Berkes et al., 2001; Diegues, 2005; Castello, 2008), essa insuficiência se deve, principalmente, a modelos desenvolvidos para pescarias de estoques monoespecíficos, típicos do clima temperado e de produção de larga escala, e à exclusividade de seu foco dado à biologia e à ecologia das populações de peixes, excluindo aspectos humanos intrínsecos à atividade da pesca, tais como mercado, organização do trabalho e aumento populacional.

Além dessas dificuldades de diálogo entre gestores da pesca e pescadores artesanais, estes começam a ser exigidos para tomada de posições ante o acirramento emergente e crescente de disputas referentes ao direito dos conhecimentos dos povos tradicionais, associados à biodiversidade e à propriedade intelectual no âmbito Organização Mundial do Comércio (OMC), no momento em que ocorre cada vez mais o reconhecimento do papel relevante das populações tradicionais para a conservação e uso sustentável dos recursos naturais, (Moreira, 2007). No escopo do Acordo sobre Aspectos dos Direitos de Propriedade Intelectual Relacionados ao Comércio (TRIPS) gerido pela OMC, os conceitos de patente e propriedade baseiam-se em uma concepção iluminista de autor, sujeito unitário, onisciente e exterior à realidade observada, em contrariedade a qualquer noção de autoria comunitária ou coletiva dos conhecimentos tradicionais ou cumulativos da natureza.

Nota-se, enfim, no âmbito dessas políticas públicas de gestão dos recursos litorâneos, uma desarticulação com o extensionismo pesqueiro. Essa fragmentação deve-se, em parte, ao que tem, ainda, predominado na comunidade científica contemporânea. Segundo Vieira (2005), é cada vez maior o fatiamento dos ecossistemas favorecido pelo mito da Torre de Babel, cujo aspecto essencial deles é a interconexão dos fenômenos vivos, em continuum com os sociais. Essa metáfora, segundo o autor, reflete a incapacidade à transposição das barreiras do entendimento entre um número crescente de especialistas com acesso a canais em escala planetária de intercâmbios de informações científicas, enclausurados, porém, em suas linguagens de matriz disciplinar. $\mathrm{Na}$ raiz desses entraves à interdisciplinaridade e ao reconhecimento dos saberes tradicionais associados à biodiversidade, encontra-se um diálogo ainda incipiente entre os conhecimentos ecológicos científicos e patrimoniais das populações extrativistas tradicionais das regiões costeiras do país. Tais conhecimentos que se valorizam cada vez mais em um cenário de transição para uma "economia verde" ou de matriz energética alternativa aos combustíveis fósseis têm sido, segundo Moreira (2007), o nó górdio da disputa no contexto do atual desenvolvimento científico e tecnológico.

\section{Extensão Participativa da Pesca Artesanal em Contexto: abordagem teórico-metodológica}

\subsection{Alguns antecedentes}

A presente proposta ATEPP foi resultante de estudos e pesquisas conduzidas no âmbito do Programa de Engenharia de Produção da COPPE/UFRJ, com ênfase em metodologias participativas de extensão universitária, associadas à gestão de recursos naturais, mais especificamente às atividades de pesca e aquicultura desde o ano de 2003 (Thiollent et al., 2003). Ela consiste basicamente em uma articulação de contribuições de dois campos interdisciplinares, a Etnociência e a Sociocognição. Como se poderá deduzir, a lógica de des-contextualização característica da ciência moderna com seus princípios de simplificação e redução, revelando a aparente dicotomia entre teoria (discurso) e prática (ação) (Diegues, 2000; Berkes et al., 2001; Vieira et al., 2005; Santos, 2009), torna-se inapropriada à complexidade da pesca artesanal

\footnotetext{
${ }^{4}$ As Reservas Extrativistas Marinhas são uma nova categoria de Áreas Marinhas Protegidas (AMP's) de iniciativa brasileira para a compatibilização da conservação da biodiversidade dos recursos pesqueiros com a pesca artesanal (Lei nº 9.985/2000 do SNUC e Instrução Normativa $\mathrm{n}^{\circ}$. 01/2007 do ICMBio). Considerando que esses planos são os instrumentos-chave da gestão dessas áreas marinhas protegidas, a falta deles torna-as, praticamente, inoperantes.
} 
associada ao seu contexto ecossistêmico. Uma iniciativa de extensão mais recente contribuiu decisivamente para a elaboração do escopo atual da proposta foi um projeto de educação ambiental de auxílio à pesquisa, ensino e à aplicação dos conhecimentos ecológicos tradicionais dos pescadores artesanais na gestão de reservas extrativistas marinhas, "Ferramenta Interativa para a Implementação de Plano de Manejo Participativo de Reserva Extrativista Marinha", com o auxílio do Programa de Conservação das Zonas Marinhas e Costeiras da Fundação SOS Mata Atlântica (Fundação COPPETEC, 2012).

\subsection{Conhecimentos maritimos tradicionais e científicos: estruturação e dinâmica}

Reunimos neste item alguns conceitos de duas áreas interdisciplinares e complementares: a Etnociência e a Sociocognição, constituídas por disciplinas das ciências humanas (antropologia, sociologia, economia, comunicação, linguística), naturais (biologia, botânica, oceanografia, neurociências) e tecnológicas (engenharia de pesca, engenharia de produção), com o objetivo de contribuir para o diálogo e formas colaborativas entre os conhecimentos ecológicos tradicionais e científicos na extensão de apoio à pesca artesanal, na perspectiva do paradigma do participatory extension. O primeiro campo parte da Linguística para estudar o conhecimento da natureza gerado cumulativamente por populações humanas tradicionais, visando extrair de enunciados linguísticos estruturas lógicas subjacentes em suas interações cognitivas com os ecossistemas naturais. O segundo campo é uma das vertentes da área de Cognição que tem por preocupação principal a estruturação e a dinâmica do ato de conhecer, envolvendo a atenção, percepção, memória, raciocínio, juízo, imaginação, pensamento, linguagem e ação. Com base em alguns dos postulados desses dois campos, esperamos contribuir para uma nova ciência pesqueira que seja adequada à complexidade da pesca artesanal: sistemas tradicionais de conhecimentos ecossistêmicos, estoques pesqueiros com alta biodiversidade em águas costeiras rasas, tecnologia de captura diversificada.

Essa proposição pressupõe a desconstrução do discurso científico que justificara a modernização com exclusão social e degradação ambiental das regiões costeiras do Brasil ao longo do século XX. Esse discurso é construído pela lógica cartesiana da descontextualização ou do desprendimento da racionalidade de sua relação com o ambiente natural e/ou social, inviabilizando qualquer possibilidade de diálogo ou cooperação entre os conhecimentos tradicionais dos pescadores artesanais e os científicos dos agentes da extensão pesqueira (Vieira, 2005; Santos, 2009). A reversão desse processo começa a poder contar com descobertas no campo da física quântica nas primeiras décadas do século XX que, ao reconhecerem ser a matéria uma das formas da energia, estilhaçaram com qualquer descrição que se pretenda única do universo, e a impossibilidade de observação científica de um fenômeno sem a inclusão do observador, inferindo que o fenômeno observado é modificado pelo ato de observação (Berkes et al., 2001; Vieira et al., 2005).

Diferentemente da extensão clássica, que se baseara em uma concepção "bancária" da produção do conhecimento $^{5}$ e estática de ecossistema, teorias etnocientíficas da conservação da natureza centram-se no uso efetivo dos recursos naturais (Ostrom, 1990; Ruddle, 2000; Diegues, 2000; 2004a), atribuindo importância aos conhecimentos milenares das populações tradicionais, usuárias dos recursos naturais para a preservação da diversidade genética e utilização sustentada das espécies de ecossistemas marinhos. Ao se introduzir a história na diversidade biótica, o que se denota é o dinamismo dos ecossistemas e a sua permanente transformação, com implicações altamente significativas para os princípios e práticas de manejo. Vários estudos reconhecem as restrições impostas pelas comunidades extrativistas tradicionais e locais como geradoras de parte da biodiversidade, sugerindo uma apreciação mais sutil das

\footnotetext{
${ }^{5}$ A “educação bancária" definida por Paulo Freire (1975) é antidialógica, por se consistir em um processo de alienação que transforma a educação em um ato de depositar, transmitir e/ou transferir, por meio da memorização mecânica, valores e conhecimentos para os educandos passivos. Estes são considerados recipientes (objetos) de conteúdos estanques de suas próprias realidades transferidos pelos educadores (sujeitos).
} 
interações humanas com os recursos pesqueiros (Ostrom, 1990; Pimbert \& Pertty, 2000; Diegues, 2000; Vieira et al., 2005). Ou seja, a forma e o grau da diversidade biológica seriam, na maioria dos ambientes continentais e marinhos, resultantes da combinação de ciclos ecológicos e climáticos com as ações humanas.

Tais conhecimentos de manejo associados à biodiversidade, designados anteriormente de CET, são definidos como sendo um corpo complexo de conhecimentos cumulativos gerados nas interações do homem com a natureza e que evolui por processos adaptativos, sendo repassado e atualizado através das gerações ao longo dos séculos (Berkes et al., 2001; Diegues, 2004a; Carneiro et al., 2012). O CET compreende a relação entre os seres vivos (incluindo os seres humanos) entre si e com o seu ambiente e não se encerra, apenas, em um mero repertório de conteúdos, mas sofisticados cálculos de ocorrências das espécies para fins de captura. Eé, com base nesses conhecimentos, que os pescadores tomam decisões de planejamento das pescarias, identificando antecipadamente as espécies que irão capturá-las e a localização delas no mar, assim como a tecnologia apropriada a ser utilizada. Essa apreensão antecipatória é feita mediante as suas "leituras" do mar, associando diversos elementos bióticos e abióticos do ecossistema marinho, tais como: migração, ciclo de vida e sazonalidade da ictiofauna, conhecimento dos habitats de ocorrência das espécies, tipos de vento e corrente, temperatura das águas, fases da lua, ardentia etc.

De um modo geral, os pescadores artesanais exprimem o ambiente marinho, suas pescarias e modos de vida em uma linguagem caracterizada pela fluidez de suas categorias, com unidades de representação instáveis, pouco claras e flexíveis, pois fortemente contextualizada. Diferentemente do CET, a linguagem clássica da biologia marinha ${ }^{6}$, por exemplo, com suas pretensões científicas de dissociação entre os sistemas naturais e o mundo vivencial, busca constituir representações invariáveis para as realidades extensionais do ambiente marinho (habitats, flora, fauna.), por meio de uma nomenclatura binominal com seus modificadores específicos (ou epítetos), segundo normas reguladoras para a atribuição de nomes científicos às espécies de seres vivos. Ou seja, enquanto a linguagem científica opera como um sistema especular (ou reflexo) sobre o real, a linguagem tradicional exprime conjuntos de conhecimentos socioculturalmente determinados e vivencialmente adquiridos (robalo água branca, parati sabão, pescada banana, outros). Apesar dessas diferenças formais entre as linguagens de pescadores e biólogos, elas possuem uma relativa coincidência por permitirem a estocagem econômica e o tratamento das experiências por meio de categorizações.

Os estudos etnocientíficos e sociocognitivos convergem para uma hipótese transversal que explicita de certo modo a estruturação e a dinâmica dos CET, oposta à versão cartesiana de descontextualização do conhecimento científico: a "realidade natural" seria um produto de nossa percepção condicionada por uma rede de estereótipos do mundo da cultura (Koch, 2002; Macedo et al., 2008; Diegues, 2004a). Para alguns estudiosos da sociocognição (Varella et al., 1992; Macedo, 2008; Koch, 2002), contrariamente à lógica da disjunção mente/corpo da versão cartesiana, a cognição humana seria pautada na experiência, isto é, uma "cognição corporificada" (embodied), ecologicamente situada. Compreende-se, assim, a cognição como sendo emergente de padrões sensório-motores de ações orientadas perceptualmente, não sendo, portanto, uma representação de um mundo pré-dado por uma mente pré-dada. O cérebro, segundo Koch (2002), reelaboraria os dados sensoriais para fins de apreensão e compreensão sob restrições impostas pelas condições culturais, sociais e históricas, ao invés de operar o dizer sobre o real segundo os princípios de identidade e equivalência.

Os exemplos a seguir demonstram que em sistemas de conhecimentos tradicionais da pesca artesanal a natureza seria algo construído perceptualmente pelo indivíduo, sendo a sua apreensão sensória sempre feita por meio de rede cognitiva produzida pelo mundo de uma cultura local. Na Figura 1, o nome popular de peixe Galo, entre tantos outros, refere-se à espécie, não ao gênero, em relação ao mundo vivido dos pescadores,

\footnotetext{
${ }^{6}$ A própria biologia contemporânea estaria, mais recentemente, revisando conceitos relacionados com a "natureza prístina" (clímax, equilíbrio ecossistêmicos, perturbação natural, fogo e regeneração, etc.) e introduzindo conceitos como coevolução ou síntese interativa de mecanismos de mudança social e natural.
} 
exemplificando a taxionomia tradicional. A referência ao mundo natural não se reduz a uma análise descritiva incontornável de um feixe de propriedades físicas dos recursos vivos, mas se faz pela introdução de suas aplicações ou usos (significação) no mundo da vida: peixe > sardinha verdadeira (Sardinella brasiliensis) > alimento $>$ isca viva; o guriri (Allagoptera arenaria) e o tucum $($ Bactris setosa $)>$ palmeiras $>$ fibra $>$ linhas e rede de pesca; outros.

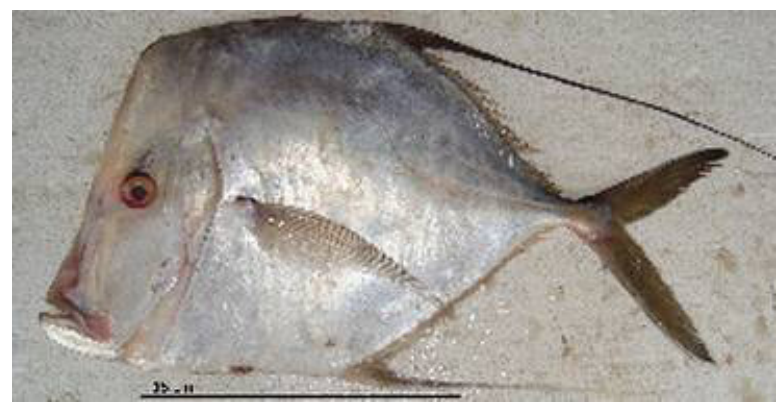

FIGURA 1 - Taxionomia tradicional do peixe galo (Selene vomer).

FONTE: Carla Isobel Elliff.

Uma pesquisa etnoictiológica na pesca artesanal do litoral de São Paulo (Ramires et al., 2007) identificou um número maior de variedades de espécies de peixes, com modificadores (ou epítetos) específicos que exprimem conjuntos de conhecimentos socioculturalmente determinados e vivencialmente adquiridos: Robalo (robalo, robalão, robalo-chato, robalo-flecha, robalo-galhudo); Manjuba (manjuba, manjubão, manjuba-prego, preguinho); Tainha (tainha-tara, rainha-grande, virote, virotão); Parati (parati, parati-guaçu, parati-pena, parati-poá, parati-chorão); Pescada (pescada, pescada-amarela, pescada-branca, pescada-sacu, outros).

Um dos marcos do paradigma emergente, em superação ao dualismo de tradição cartesiana, foi a criação da Convenção da Diversidade Biológica (CDB) no final do século XX, proporcionando o surgimento da noção da biodiversidade, cujo princípio admite a possibilidade de coexistência harmônica entre sociedade e natureza, rompendo com a concepção até então dominante da ecologia profunda, que julgara ser incompatível o convívio dos povos tradicionais com a proteção e utilização sustentável da natureza (Diegues, 2004a). Essa interatividade entre a natureza e as ações humanas pode ser ilustrada, também, pelo conceito de maritimidade proposto por Diegues (2004b) que define o mar como um produto cultural e social, não somente como um objeto físico esfacelado pela especialização das ciências, contribuindo, deste modo, para uma abordagem dialógica e interdisciplinar da extensão pesqueira, desvinculada do positivismo científico ${ }^{7}$.

\subsection{Pesquisa-ação participativa da Assistência Técnica de Extensão Pesqueira Participativa- ATEPP}

\section{a) Interatividade e recursividade}

Tendo em vista a demanda pelo compartilhamento entre CET e conhecimentos científicos para uma extensão pesqueira participativa na perspectiva do paradigma do participatory extention, alternativos ao modelo clássico de transferência de conhecimentos e tecnologia da pesca, propõe-se aqui uma pesquisa-ação participativa (PAP) mediada pela interatividade e em sentido recursivo, uma modalidade de intervenção coletiva para a resolução de problemas através da interação entre os momentos investigativo (pesquisa) e ativo (ação ou decisão) mediatizada pela reflexão coletiva com um poder distribuído entre seus participantes (Thiollent et al., 2003; Dionne, 2007). No caso desta presente proposta, a PAP é reconfigurada como uma modalidade de metodologia interativa para projetos complexos (Carneiro, 2003; Carneiro \& Vieira, 2013), conforme fluxograma da Figura 2, estruturada

\footnotetext{
${ }^{7}$ Até recentemente, o mar era entendido, exclusivamente como parte do mundo natural, marcado pela existência dos fluxos das marés, e habitado por seres vivos não humanos, objeto de estudos da oceanografia e da biologia marinha. O objetivo deste trabalho é mostrar que o mar e os oceanos, desde os primórdios da humanidade, foram objetos de curiosidade, de conhecimento, de ricas simbologias e de práticas culturais antigas, ligadas à pesca, coleta e navegação. Todas essas atividades foram exigindo um conhecimento crescente do mar e seus fenômenos, a partir das práticas culturais que foram se acumulando durante vários milênios (Diegues, I SEGAP, 2004).
} 
de modo interativo com uma dinâmica recursiva, com evoluções espiraladas, ao invés de lineares, e a ênfase no papel pragmático da linguagem - isto é, voltado para a interação social por meio da linguagem e/ou constituída por ela - e concebida como uma atividade essencialmente interativa, assegurando, assim, o compartilhamento dos conhecimentos ecológicos tradicionais e científicos nas atividades de assistência técnica e extensão pesqueira.

A aplicação da metodologia é bastante flexível, podendo ser facilmente adaptada a realidades semelhantes. Fundamentalmente, ela foi concebida para projetos complexos, apropriados a problemas pouco estruturados ou nebulosos, demandando abordagens interdisciplinares e a participação direta dos sujeitos da realidade focal e em contexto. A dimensão interativa da metodologia deve-se à relevância atribuída ao papel pragmático da linguagem - esta é concebida como uma atividade essencialmente interativa por pressupor a presença sempre de uma pluralidade de pessoas ou vozes. Por essa razão, a postura dialógica da equipe técnica se faz necessária. As ações do projeto não se propagam no vácuo ou em um movimento retilíneo uniforme, mas em uma realidade complexa (setting) constituída de redes de múltiplas conexões cognitivas e ambientais, demandando, pois, discurso técnico contextualizado, aberto, ao diálogo, menos demonstrativo e mais argumentativo.

\section{b) Contexto: cadeia produtiva da pesca artesanal}

Na perspectiva da metodologia proposta, a abordagem de cadeias produtivas da pesca artesanal deve proporcionar à extensão pesqueira uma visualização das atividades de captura e cultivo de organismos marinhos de forma integral e sistêmica, portanto não fragmentária e nem descontextualizada de suas realidades de produção e consumo. Procuramos sintetizar o conceito de cadeia produtiva aplicado à pesca artesanal como sendo uma sucessão de operações de produção e distribuição integradas, realizadas por diversos segmentos: fornecimento de suprimentos, realização da captura e cultivo do pescado, transformação/distribuição do pescado in natura ou processado, comercialização e consumo final.

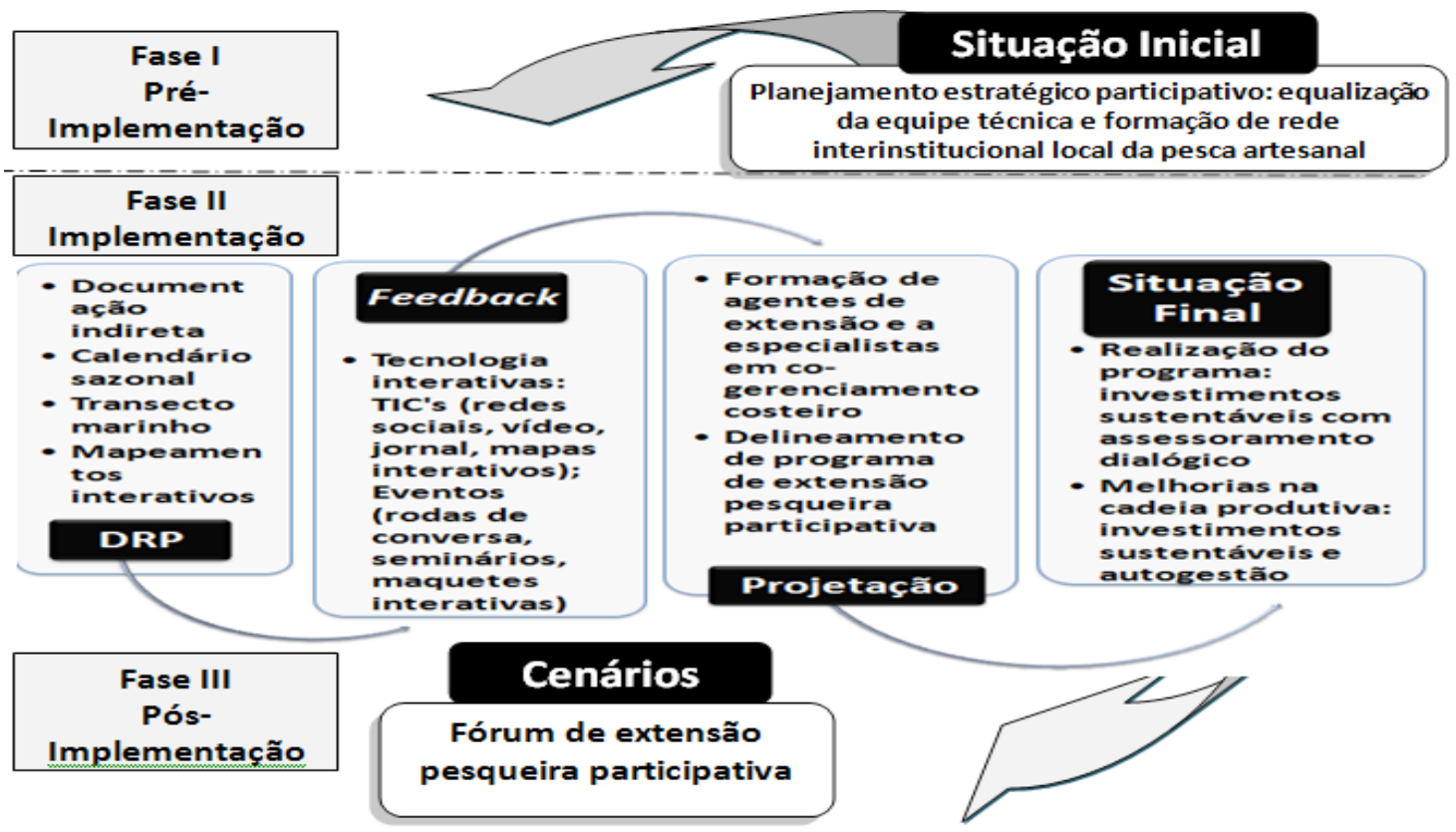

FIGURA 2 - Fluxograma da metodologia ATEPP em contexto: recursividade e interatividade.

FONTE: Os Autores. 
Historicamente, as políticas de modernização das regiões costeiras acarretaram a desvalorização da pesca artesanal por falta de investimentos públicos em três segmentos, principalmente, na cadeia produtiva: suprimentos, pesca e transformação. Em suprimentos, a introdução de apetrechos industrializados em substituição aos artesanais e a perda para o mercado da propriedade de embarcações tem gerado, crescentemente, dependência tecnológica e econômica. A ocupação desordenada das regiões litorâneas (acesso livre, falta de gerenciamento costeiro e de ordenamento pesqueiro e de planos de manejo de áreas marinhas protegidas) tem impactado diretamente na redução da biodiversidade marinha, acarretando a diminuição dos estoques pesqueiros e, consequentemente, no declínio das pescarias artesanais. Na transformação, a falta de investimentos públicos em infraestrutura de armazenagem com resfriamento para o pescado capturado ou cultivado, produto altamente perecível, e logística para a sua distribuição, acarreta a terceira perda para o pescador (Mendonça et al., 2010).
Na Tabela 1, ressaltamos algumas ações estruturantes para a sustentabilidade da pesca artesanal que podem ser tomadas em cada um dos segmentos da sua cadeia produtiva, promovendo maior independência e autonomia dos pescadores em relação ao mercado, agregação de valor ao pescado com a redução da CPUE (Captura por Unidade de Esforço), melhoria da precificação do pescado tanto para pescadores quanto para consumidores.

\section{c) Delineamento: fases, tecnologia e governança}

\section{FASES}

AATEPP consistiria por um processo recursivo de três fases basicamente: Fase I - Pré-Implementação, Fase II - Implementação e Fase III - Pós-Implementação. A primeira centra-se no planejamento estratégico participativo da ATEPP em contexto. A segunda fase consiste na realização da pesquisa-ação participativa (PAP) para fins de investimentos sustentáveis a montante e a jusante

TABELA 1 - Ações estruturantes para a sustentabilidade da cadeia produtiva da pesca artesanal.

\begin{tabular}{|c|c|}
\hline SEGMENTOS & AÇÕES ESTRUTURANTES \\
\hline Suprimentos & $\begin{array}{l}\text { - Compra coletiva e/ou através de pessoa jurídica (colônia, associação, cooperativa, ONG etc.) de apetre- } \\
\text { chos, combustível, motores, gelo etc. }\end{array}$ \\
\hline $\begin{array}{l}\text { Pesca (captura e } \\
\text { cultivo) }\end{array}$ & $\begin{array}{l}\text { Pesquisa e aplicação dos conhecimentos ecológicos tradicionais, por meio de "acordos de pesca", em pla- } \\
\text { nos de manejo de áreas marinhas protegidas e na gestão sustentável do litoral para o ecodesenvolvimento }\end{array}$ \\
\hline Transformação & - $\quad$ Aumento de renda com diminuição da CPUE e do preço para o consumidor final \\
\hline \multirow{2}{*}{ Comercialização } & - $\quad$ Comércio convencional e rede de mercado justo ou solidário \\
\hline & - $\quad$ Agregação de valor por meio de certificação de sustentabilidade do pescado \\
\hline
\end{tabular}

FONTE: Os Autores.

\footnotetext{
${ }^{8}$ Os arranjos institucionais devem oferecer uma maior visibilidade das instituições locais com suas modalidades endógenas de manejo e apropriação dos recursos aquáticos, potencializando a criação e implementação de formatos institucionais no sentido bottom up, com espaços interativos que propiciem as conexões interinstitucionais locais/globais para a gestão simultânea dos recursos naturais em múltiplas escalas.
} 
na cadeia produtiva da pesca artesanal, associados à formação e intensificação de arranjos institucionais transescalares (Berkes, 2005; Carneiro et al., 2012 ${ }^{8}$ ), tendo por finalidade a melhoria dos preços do pescado para os pescadores e consumidores com a redução do CPUE. A pesquisa-ação participativa (PAP) inicia-se com um diagnóstico rápido participativo (DRP) da situação inicial e encerra-se em uma situação final (desejada) pelos pescadores artesanais, por meio de um processo de projetação mediado por feedbacks.

\section{$\underline{\text { TECNOLOGIA }}$}

A metodologia de extensão pesqueira participativa, por implicar conexões sociocognitivas entre racionalidades diferentes (conhecimentos tradicionais e científicos) e entre sujeito e ambiente, vale-se de da tecnologia como um agenciamento de atividades compartilhadas - ou compromissos (co-ordination of commitments). O conceito de tecnologia passa referir-se ao projeto de práticas sociais por meio de artefatos, não se encerrando, portanto, em artefatos físicos somente. Ela é conhecimento aplicado, isto é, um "saber-fazer", união teoria-prática ou conhecimento-ação.

Toda tecnologia consistiria, portanto, de artefatos físicos e simbólicos com propriedades cognitivas (conceitos, teorias) e normativas (regras, modos de fazer) com duas funções complementares: econômica - atendimento à satisfação das necessidades materiais e imateriais das sociedades; criativa - a capacidade de transformação dos objetos em artefatos. Essa visão afasta-se da noção do senso comum da tecnologia entendida como o projeto e utilização de técnicas e instrumentos, com base em conhecimento aplicado para fins práticos. Essa concepção pragmática de tecnologia, alternativa à sua concepção instrumental da ciência moderna, encontra-se fundamentada em obras de Flores (1989) e de Lévy (1994). Para Flores, a tecnologia não é um projeto (design) de artefatos físicos para fins econômicos e técnicos, mas um projeto de práticas sociais por meio de artefatos, não se encerrando, portanto, em instrumentos ou ferramentas somente. Essa noção de tecnologia como um projeto de práticas sociais por meio de artefatos retoma o significado etimológico do grego téchne, a transformação da realidade natural em uma realidade construída para fins de subsistência e sobrevivência do ser humano, com base na natureza inteligente do homem, tal como se caracterizam as mediações dos povos tradicionais com a biodiversidade.

Algumas das ferramentas sugeridas por Berkes et al. (2001) para a pesquisa junto a pescadores de pequena escala ou artesanais exemplificam a noção de tecnologia apropriada à metodologia ATEPP: (a) Calendários sazonais - inserção em um calendário circular de sínteses feitas por alguns grupos de pescadores das espécies principais e seus padrões sazonais de captura de acordo com o ponto de vista dos pescadores, ao invés de se restringir ao calendário cristão; (b) Mapeamento interativo - identificação do ecossistema marinho da região para fins de planejamento de manejo participativo de áreas marinhas protegidas e do cogerenciamento do litoral, com suportes de desenhos geométricos e de sistemas de georreferenciamento com interface nos conhecimentos ecológicos tradicionais dos pescadores; (c) Transecto caminhadas com informantes-chaves por rotas na zona costeira utilizadas por membros das comunidades de pescadores, devendo, também, o método ser adaptado por mergulhadores em pesquisas rápidas submarinas para observação da situação de corais, espécies bioinvasoras, bancos vegetados ou bases da cadeia trófica da ictiofauna marinha na região focalizada.

\section{GOVERNANCA}

Ressaltamos neste tópico que se torna imprescindível para a resiliência da pesca artesanal a intensificação de conexões interinstitucionais ou arranjos institucionais transescalares, isto é, formatos facilitadores das interações em diversos níveis de escalas tanto verticais (instâncias organizacionais) quanto horizontais (espaciais). A literatura sobre recursos de uso comum contemporânea tem evidenciado que a gestão centrada no nível local ou nos níveis mais altos das organizações não pode dar conta de sua efetividade por si mesma (Berkes, 2005). A globalização econômica é uma das principais razões para se elevar cada vez mais a intensificação dessas conexões entre as escalas institucionais. No caso dos pescadores e demais populações e povos tradicionais, que têm no manejo dos recursos naturais comuns (Common pool resources - CPRs) sua principal fonte de subsistência e reprodução social, esses novos designs institucionais tendem a crescer na medida em que seus conhecimentos 
tradicionais associados à biodiversidade se transformam em ativos econômicos e ambientais. Como dissemos antes, a crise global da pesca não se reduz, apenas, à diminuição da abundância dos recursos pesqueiros por causas antrópicas, mas um indicador de insustentabilidade dos padrões de produção e consumo das sociedades urbano-industriais.

\section{Projeto Ardentia: uma Iniciativa Promissora da Assistência Técnica de Extensão Pesqueira Participativa - ATEPP}

O projeto "Projeto Ardentia 9 - extensão participativa da pesca artesanal na Região Costa do Sol" consiste em um laboratório de aplicação e estudo da proposta metodológica de ATEPP com base em pressupostos etnocientíficos e sociocognitivos delineados anteriormente. O projeto, elaborado para fim de geração de renda e oportunidade de trabalho na cadeia produtiva da pesca artesanal, obteve a aprovação de patrocínio da Petrobras S.A., através do Programa Petrobras Socioambiental, para a sua realização.

\subsection{O Contexto socioecológico}

\section{a) Abrangência e delimitação.}

A atuação do projeto deverá abranger, parcialmente, a região Costa do Sol, localizada no litoral norte do Estado do Rio de Janeiro, contemplando pontos de pesca e pesqueiros, instituições de organização do trabalho, lazer e moradia em três municípios: Armação dos Búzios, Arraial do Cabo e Cabo Frio. A região é avaliada como de "Extrema Importância Biológica", grau máximo de conservação da biodiversidade marinha no Brasil, possuindo condições especiais e únicas na costa brasileira, em razão da ocorrência sazonal do raro fenômeno marinho da "ressurgência" (upwelling), afloramento de águas frias, originárias do polo sul, e ricas em nutrientes, proporcionando uma biodiversidade marinha altamente abundante, com grande benefício à pesca artesanal, sendo seu epicentro de ocorrência o litoral de Arraial do Cabo (Fundação COPPETEC, 2009).

\section{b) Aspectos socioeconômicos.}

Apesar das qualidades ecossistêmicas da região favoráveis à pesca artesanal, ela é emblemática em relação aos impactos das políticas de modernização do Brasil que atingiram o setor da pesca artesanal na costa brasileira. O desenvolvimento urbano-industrial ocorrido na região durante as últimas décadas configurou-se como exógeno, sendo incapaz de assegurar alguma correspondência direta entre o aumento do PIB e melhoria da qualidade de vida, redução da pobreza e valorização das culturas dos povos tradicionais locais como estratégia de conservação sustentável dos ecossistemas marinhos e costeiros. O boom econômico da região nas últimas décadas promovido pelas indústrias do turismo e da exploração offshore de petróleo ocorreu acompanhado por índices negativos: queda no IDH, crescimento da pobreza e da desigualdade social, sendo a pesca artesanal o segmento socioeconômico mais atingido.

A pesca na região, juntamente com a pesca industrial, mantém-se na terceira posição do ranking da produção pesqueira do Estado do Rio de Janeiro, dividindo o primeiro e segundo lugar, respectivamente, com a região metropolitana do Rio de Janeiro e a de Angra dos Reis (FIPERJ, 2011). Entre as espécies pelágicas mais capturadas em um dos municípios da Região Costa do Sol no ano de 2009, município de Arraial do Cabo, foram a espada (Trichiurus lepturus) - 57.975kg, a enchova (Pomatomus saltatrix) $27.227 \mathrm{~kg}$; a sardinha verdadeira (Sardinella brasiliensis,) $14.430 \mathrm{~kg}$. As modalidades de capturas mais utilizadas incluem o arrasto de praia, espinhel, linha de fundo, zangarejo, cultivo de

\footnotetext{
${ }^{9}$ A "ardentia" é o nome dado pelos pescadores brasileiros ao brilho produzido pela movimentação de cardume de certos peixes pelágicos, como a sardinha, em noites de lua nova, indicando o momento de lançar a rede de cerco, ainda que hoje a localização dos cardumes seja feita por sonares e radares (Diegues, 1983). Essa luminosidade no mar é também conhecida como bioluminescência ou "luz fria", produzida, pois, por organismos marinhos, como os fitoplânctons nas camadas das águas superiores da água do mar.
} 
mexilhão, etc. E as embarcações mais comuns são "botes de boca aberta", canoas, caícos, traineiras. A maioria dos pescadores artesanais $(60,52 \%)$ não possui embarcação de pesca própria, descaracterizando o conceito legal de pescador profissional artesanal como sendo aquele que possui autonomia e utiliza recursos próprios na atividade pesqueira. Entretanto, apesar do grande valor agregado ao pescado da região, a baixa rentabilidade do trabalho da pesca insere a maioria dos pescadores, paradoxalmente, nas faixas da pobreza e da indigência (Fundação COPPETEC, 2009).

Uma hipótese para a reversão desse quadro paradoxal de empobrecimento seria a promoção da autonomia e da autogestão da cadeia produtiva pelos pescadores artesanais, pressupondo a falta de conexões entre seus segmentos como um dos fatores da desvalorização da pesca artesanal e não a redução da abundância apenas. A rigor, o pescador artesanal, por deter conhecimentos do manejo pesqueiro pela tradição, pode recorrer à economia de subsistência ante a iminência da pobreza e da indigência, desde que possa dispor dos serviços ecossistêmicos marinhos e/ou aquáticos. Segundo o estudo da cadeia produtiva na região (Mendonça et al., 2010), verificou-se que os segmentos da cadeia produtiva da pesca artesanal seguintes à captura (distribuição, beneficiamento e comercialização) apresentam pontos de estrangulamento que parecem ter influência decisiva na diminuição da rentabilidade dos pescadores. A reorganização da cadeia produtiva para a redução dos custos e melhoria da qualidade do pescado poderá fortalecer o setor e melhorar a qualidade de vida do pescador artesanal. Este estudo sugere ainda a importância de entrepostos de pesca para o recebimento, estocagem, beneficiamento e comercialização do pescado como parte da estratégia de redução da trajetória do pescado até o consumidor final, beneficiando as duas pontas da cadeia - pescadores e consumidores. Conforme demonstra esse estudo de Mendonça et al. (2010), as perdas para o pescador nos segmentos da cadeia produtiva - transformação, comercialização e consumo - oscilam de $100 \%$ a $800 \%$. Como exemplo, a compra e venda da Sardinha verdadeira (Sardinella brasiliensis) pelo pescador após sua captura: $1 \mathrm{~kg}$ dessa espécie é vendido por ele a $\mathrm{R} \$ 1,00$ para o atravessador que, por sua vez, o revende a $\mathrm{R} \$ 2,00$ aos mercados internos e externos à região.
Frente ao quadro de desvalorização da pesca artesanal pelo mercado globalizado, o projeto Ardentia propõe realizar, por meio de uma metodologia de assistência técnica e extensão pesqueira participativa (ATEPP), investimentos ao longo da cadeia produtiva da pesca artesanal em três municípios da Costa do Sol, Armação dos Búzios, Arraial do Cabo e Cabo Frio, para geração de renda e melhoria das condições de vida e trabalho dos pescadores artesanais sem implicar o aumento da produção pesqueira, contribuindo, assim, para a sustentabilidade do setor em associação ao futuro eco-desenvolvimento da região Costa do Sol.

\subsection{Metodologia ATEPP}

Como proposta alternativa a extensão dissociada dos saberes cumulativos do mar de povos e populações costeiras tradicionais, o objetivo do Projeto Ardentia deverá ser alcançado por meio de uma metodologia ATEPP, constituída pela pesquisa-ação participativa mediada pela interatividade e em uma progressão recursiva dentro das seguintes fases:

\section{Fase I: Pré-Implementação: Planejamento Estratégico Participativo}

Com o propósito de se fazer uma mediação entre a concepção do projeto e sua realização, serão desenvolvidos os seguintes eventos:

- Workshop: equalização da equipe técnica

- Seminário: apresentação pública do projeto e constituição de rede interinstitucional regional com cerca de 30 instituições da região que já declararam formalmente apoio a proposta do projeto (colônias e associações de pescadores e maricultores familiares, órgãos públicos municipais, estaduais e federais de gestão e extensão pesqueira).

\section{Fase II: Implementação: Programa ATEPP em Contexto}

Esta, por sua vez, é constituída por 3 etapas da pesquisa-ação participativa (PAP), a saber:

\section{Etapa: Diagnóstico rápido participativo (DRP)}

Atualização de demandas da pesca artesanal no contexto do litoral da Região Costa do Sol para o apoio 
do Programa ATEPP do projeto Ardentia, com vistas à sustentabilidade da atividade de produção de pescados de pequena escala em associação ao ecodesenvolvimento litorâneo.

\section{$2^{a}$. Etapa: Projetação}

Capacitação de Agentes ATEPP e formação de especialistas em gerenciamento costeiro, com base nos resultados do DRP, tendo em vista a participação no Projeto Ardentia e a elaboração de projetos com planos de negócios para o acesso dos recursos do programa do projeto Ardentia e, também, de programas de políticas púbicas de extensão da pesca artesanal.

\section{$3^{a}$. Etapa: Investimentos Sustentáveis}

Esta etapa consiste, por meio do assessoramento dialógico, na aplicação de recursos do projeto Ardentia e no acesso dos pescadores artesanais, maricultores familiares e agentes de turismo de base comunitária a programas de políticas públicas para comunidades tradicionais da pesca artesanal da região Costa do Sol. Pelo projeto, deverão ser disponibilizados, aproximadamente, $\mathrm{R} \$$ $350.000,00$ em suprimentos para a cadeia produtiva da pesca artesanal e mais $\mathrm{R} \$ 100.000,00$ em assessoramento dialógico, visando à melhoria das condições de trabalho e de preços para pescadores e consumidores de pescado e frutos do mar. Entre as ferramentas e equipamentos tecnológicos a serem adquiridos para os pescadores, encontram-se apetrechos, embarcações, câmaras frias, etc. a serem introduzidos nos diversos elos da cadeia produtiva (suprimentos, captura/cultivo, desembarque, distribuição e comercialização), além de incentivos às artes tradicionais e ao turismo de base comunitária, agregando valor à pesca artesanal.

O Programa ATEPP compreende, assim, um conjunto de investimentos sustentáveis para o setor da pesca artesanal da região Costa do Sol mediados por uma assistência técnica dialógica na extensão pesqueira participativa com enfoque multidisciplinar. Para esse assessoramento dialógico, serão realizadas dezenas de oficinas interativas, articuladas com um programa de educação voltado para a profissionalização da pesca e o cogerenciamento do litoral na perspectiva de um ecodesenvolvimento da região litorânea, contribuindo para a redução da pobreza e desigualdade social, com satisfação das necessidades materiais e imateriais das populações extrativistas tradicionais, assegurando a prudência ecológica e a participação na gestão do litoral.

$\mathrm{O}$ modelo proposto aqui de assessoramento da ATEPP, alternativo à concepção "bancária" da extensão, com processos padronizados, indiferentes à realidade de sua atuação, reúne duas modalidades, a assessoria temática e o acompanhamento de processos de solução de problemas (Brose, 2004). Enquanto que a assessoria temática restringe-se à observação direta da evolução e da qualidade das decisões sem interferência nestas, o segundo modelo caracteriza-se pela observação participante, passando de facilitador para moderador de processos de grupos e trabalho. Eles têm em comum o pressuposto de que todo o problema de extensão é em si complexo, tornando imprescindíveis as estruturas construtivas de comunicação para assegurarem a reciprocidade entre a assessoria técnica e o grupo demandante ou envolvido diretamente com a realidade imediata focalizada pelo projeto.

\section{Fase III: Pós-Implementação - Fórum de Extensão Pesqueira}

A última fase consistirá da realização de um fórum regional de extensão participativa da pesca artesanal para a avaliação do programa de extensão pelos participantes dos três municípios envolvidos tendo em vista a criação de alguma unidade ou rede regional de gestão compartilhada da cadeia produtiva da pesca artesanal e formulação de diretrizes de continuidade e/ou recomendações de ações promissoras para a sustentabilidade do setor na perspectiva do ecodesenvolvimento da região Costa do Sol.

\section{Conclusão}

Com base na literatura consultada e na iniciativa do Projeto Ardentia, podemos deduzir que é oportuno e viável o design de novas metodologias apropriadas à extensão pesqueira voltada para a pesca artesanal no litoral brasileiro nas perspectivas do participatory extention, alternativas ao modelo clássico de assistência técnica e extensão pesqueira/rural que provocou tantos efeitos danosos a esse setor de manejo tradicional dos 
recursos dos ecossistemas das regiões costeiras do Brasil. Essa oportunidade não se reduz, porém, ao discurso de princípios de uma extensão participativa e dialógica desvinculados das ações, conforme observamos nas atuais políticas públicas do Governo Federal, mas em uma pragmática, isto é, em uma aliança entre o dizer e o fazer, superando, assim, a descontextualização cartesiana, um dos pilares do pensamento científico moderno e, também, a concepção "bancária" da extensão.

Inicialmente, visamos desconstruir alguns estereótipos em relação à pesca artesanal no Brasil, onde esta atividade continua sob os efeitos negativos de uma série de classes de impactos de instituições em níveis superiores e abrangentes. Na sequência, focalizamos os impactos socioeconômicos na pesca artesanal e antrópicos nas regiões litorâneas brasileiras, provocados pelos processos de modernização, com seus efeitos danosos à exacerbação da pobreza e às mudanças ecossistêmicas das regiões costeiras. Procuramos depois ressaltar limitações da atuação extensionista pesqueira orientada pelos modelos lineares e disjuntivos da ciência moderna, estruturados por princípios cartesianos do dualismo e da descontextualização para realidades ecossistêmicas da pesca artesanal que se presume complexas, pois percebidas sempre como algo inacabado e incompleto e constituídas por interconectividades e dinâmicas inextricavelmente múltiplas.

Essas limitações da ciência pesqueira, por exemplo, conforme apontam Berkes et al. (2001), consistem na falta de um conjunto de ferramentas com métodos efetivos para se lidar com a complexidade, que não se reduz à simplicidade dualística (sujeito x objeto, biologia $\mathrm{x}$ cultura etc.). Novas diretrizes que têm sido delineadas para a gestão da pesca artesanal no mundo não limitam mais a sua atenção, somente, aos estoques e à dinâmica de populações de peixes, mas também às dimensões humanas da pescaria. Além disso, a área do Direito Ambiental vê-se diante de seu maior desafio atual que é a busca por soluções jurídicas inéditas para o reconhecimento do direito reivindicado pelas sociedades tradicionais à proteção dos seus conhecimentos ancestrais associados à biodiversidade, como o CET dos pescadores artesanais costeiros. Tais conhecimen- tos, como dito anteriormente, já são considerados o "nó górdio" nas disputas mais inflamadas no contexto atual de áreas de fronteiras do desenvolvimento científico e tecnológico, como a biotecnologia e a biossegurança do patrimônio genético. Nesse contexto, seria paradoxal, do ponto de vista sociocognitivo, obter qualquer concordância ou consenso entre os atores sociais do setor da pesca artesanal por meio de raciocínios assertivos e apodíticos da lógica dualística que reportam as suas convicções à evidência, inviabilizando qualquer possibilidade de diálogo. Ao contrário destes, as negociações e as tomadas de decisões complexas requerem raciocínios argumentativos que pressupõem uma apreensão perceptual dos dados da realidade, assim como dissera Heisenberg ser impossível a observação de um fenômeno sem a inclusão do observador.

Ressaltamos que a proposta metodológica de extensão participativa da pesca artesanal em contexto aqui delineada, juntamente com suas ações promissoras estruturantes, é condizente com o enfoque e a tecnologia de planejamento interativo do ecodesenvolvimento do litoral (Vieira, 2005; Pollete et al., 2006; Carneiro, 2003). Esta concepção que designa um estilo de desenvolvimento endógeno, participativo e integrado, assim como o paradigma da biodiversidade, busca aliar a satisfação das necessidades humanas fundamentais (materiais e intangíveis) com a prudência ecológica sobre uma base de economia negociada e contratual. Para isso, pressupõe os sistemas de conhecimentos das populações tradicionais dos pescadores artesanais das regiões costeiras como pontos de referências para o acesso e uso sustentável dos recursos marinhos e costeiros, sendo, portanto, um dos fatores decisivos para a efetivação de novos padrões de gestão adaptativa à complexidade das dinâmicas ecossistêmicas não lineares e à interatividade entre a biodiversidade e a pesca artesanal. Nesse sentido, compartilhamos da opinião de Berkes et al. (2001) sobre algo, no mínimo, inusitado para o Iluminismo, que se acreditava estar em rota de colisão com a modernidade: o renascimento da tradição, talvez, devido aos excessos da própria "modernização" e do fracasso dos modelos de desenvolvimento autônomos em relação a quaisquer contextos. 


\section{Referências}

Aburto-Oropeza, O.; Ezcurra, E.; Danemann, G.; Valdez, V.; Murray, J.; Sala, E. Mangroves in the Gulf of California increase fishery yields. PNAS, 105(30), 10456-10459, 2008.

Berkes, F. Conexões Institucionais Transescalares. In: Vieira, P. F; Berkes, F; Seixas, C. S. (Orgs.). Gestão integrada e participativa de recursos naturais: conceitos, métodos e experiências. Florianópolis- Secco/APED, 2005.

Berkes, F.; Mahon, R.; McConney, P.; Pollnac, R. B.; Pomeroy, R. S. (Orgs.). Managing small-scale fisheries: Alternative Directions and Methods. International Development Reaserch, Centre, Ottawa, 2001.

Brose, M. (Org.) Participação na Extensão Rural - experiências inovadoras de desenvolvimento local. Porto Alegre: Tomo Editorial, 2004.

Callou, A. B. F. A voz do Mar, Construção Simbólica da Realidade dos Pescadores Brasileiros pela Missão do Cruzador “José Bonifácio”. São Paulo: Tese de Doutorado em Ciências da Comunicação. ECA/USP, São Paulo, 1994.

Carneiro, A. M. M. "Ferramenta de Linguagem" para metodologias interativas de projetos de extensão. In: Thiollent, M; Branco, A; Guimarães, R; Araújo Filho, T. Extensão Universitária - conceitos, métodos e práticas. Rio de Janeiro: SR5/ UFRJ, 2003.

Carneiro, A. M. M.; Vieira, L. F. Ferramentas Interativas para a Conservação Sustentável de Áreas Marinhas Protegidas. Revista de Comunicação e Educação Ambiental, 3, 1-38, 2013.

Carneiro, A. M. M.; Vieira, L. F.; Moraes, E. A. Conhecimentos tradicionais da pesca artesanal para a conservação sustentável do mar: valores patrimoniais do espaço marítimo na Reserva Extrativista Marinha de Arraial do Cabo - RJ. Rio de Janeiro: Editora COPPE/UFRJ, 2012, v.1. p.54. Disponível em: http:// www.ardentia.com.br/downloads/Edicao_Revisada_isbn_97885-285-0224.pdf

Carvalho, F.; Callou, A. Extensão pesqueira e desenvolvimento local: a experiência da Secretaria Especial de Aqüicultura e Pesca no Estado de Pernambuco, 2003-2006. INTERAÇÕES, 9(1), 65-76, 2008.

Castello, L. Re-pensando o estudo e o manejo da pesca no Brasil. Pan-American Journal of Aquatic Sciences, 3(1), 1722, 2008.

Costanza, R.; d'Arge, R.; Groot, R. de; Farberparallel, S.; Grasso, M.; Hannon, B.; Limburg£star, K.; Naeem, S.; O’Neill,
R. V.; Paruelo, J.; Raskin, R. G.; Sutton, P.; van den Belt, M. The value of the world's ecosystem services and natural capital. Nature, 387, 253-260, 1997.

Diegues, A. Pescadores, Camponeses e Trabalhadores do Mar. São Paulo: Editora Ática, Ensaios 94, 1983.

Diegues, A. Etnoconservação: novos rumos para a proteção da natureza nos trópicos. São Paulo: NUPAUP/USP - HUCITEC, 2000.

Diegues, A. O Mito Moderno da Natureza Intocada. São Paulo: Editora Hucitec/NUPAUB, 2004a.

Diegues, A. A Interdisciplinaridade nos Estudos do Mar: o Papel das Ciências Sociais. In: Anais do I SEGAP, Rio de Janeiro, COPPE/UFRJ, Apoio: FINEP/PETROBRAS, 2004b.

Diegues, A. Valores Patrimoniais da Cultura Tradicional da Pesca Artesanal de Arraial do Cabo. In: FUNDAÇÃO COPPETEC. Relatório Técnico II - Projeto Ressurgência, Rio de Janeiro, SAGE/COPPE/UFRJ, Apoio: Programa Petrobras Ambiental - PPA, 2007.

Dionne, H. A Pesquisa-Ação para o Desenvolvimento Local. Brasília: Liber Livro Editora, 2007.

FAO/UNEP. The World State of Fishery and Aquaculture. 2012. Acesso: http://www.fao.org.

Flores, F. Inventando la Empresa del Siglo XXI. Santiago: Eidicones Pedagógicas Chilenas S. A, Colección HACHETTE/ Comunicación, 1989.

FUNDAÇÃO COPPETEC/UFRJ. Relatório Técnico III: Design de Ferramentas Interativas e Diretrizes para o Plano de Manejo Participativo da Reserva Extrativista Marinha de Arraial do Cabo - RJ. Rio de Janeiro, 2012.

FUNDAÇÃO COPPETEC. Projeto Ressurgência: relatório técnico IX - Projeto Ressurgência, Rio de Janeiro, SAGE/ COPPE/UFRJ, Apoio: Programa Petrobras Ambiental PPA,SAGE/COPPE/UFRJ, 2009.

IBAMA/MMA. Produção Estimada e Participação Relativa da Pesca Extrativista, Industrial, Artesanal e Aqüicultura no Brasil, por Unidade da Federação. Brasília: SEAP-PR, 2005.

Kalikoski, D. C. Áreas Marinhas Protegidas, Conservação e Justiça Social - considerações à luz da Teoria dos Comuns. In: Prates, A. P.; Blanc, D. (Orgs.). Áreas Aquáticas Protegidas como Instrumento de Gestão Pesqueira. Série: 'Áreas Protegidas do Brasil. 4. Brasília: MMA/SBF, 2007. 
Koch, I. Desvendando os Segredos do Texto. São Paulo: Cortez Editora, 2002.

LÉVY, Pierre. As Tecnologias da Inteligência. Rio de Janeiro: 34 Literatura S/C Ltda, 1993.

Lima, A.; Kroeff, D.; Corezola, F; Brutto, L. Planejamento Participativo e Desenvolvimento Sustentável em Comunidades Tradicionais - comunidades indígenas, de pescadores artesanais e remanescentes de quilombos. In: Brose, M. (Org.) Participação na Extensão Rural - experiências inovadoras de desenvolvimento local. Porto Alegre: Tomo Editorial, 2004.

Macedo, A. M.; Feltes, H.; Farias, M. Cognição e Linguística: explorando territórios, mapeamentos e percursos. Porto Alegre: Educs/Edipucrs, 2008.

Mendonça, F.M.; Valle, R.; Coutinho, R. A Cadeia Produtiva da Pesca Artesanal em Arraial do Cabo: análise e propostas de melhoria. In: XXX ENEGEP, São Carlos, SP, Brasil, 2010.

MILLENNIUM ECOSYSTEM ASSESMENT - MEA: Ecosystem and Human Well-being: Synthesis Reports: http://www. millenniumassessment.org/en/, March, 2005.

Moreira, E. Conhecimento Tradicional e a Proteção. $T \& C$ Amazônia, 5(11), 2007.

Oliveira, O; Silva, V. O Processo de Industrialização do Setor Pesqueiro e a Desestruturação da Pesca Artesanal no Brasil a partir do Código de Pesca de 1967. Sequência, n. 65, p. 329357, dez. 2012.

Ostrom, E. Governing the commons. The evolution of institutions for collective action. Cambridge, UK: Cambridge University Press, 1990.

Pádua, J. A. Um Sopro de Destruição - pensamento político e crítica ambiental no Brasil escravista (1786 - 1888). Rio de Janeiro: Jorge Zahar Editor, 2004.

Pimbert, M. P.; Pretty, J. Parques, Comunidades e Profissionais: Incluindo "Participação" no Manejo de Áreas Protegidas. In: Diegues, A. Etnoconservação: novos rumos para a proteção da natureza nos trópicos. São Paulo: NUPAUP/USP - HUCITEC, 2000..
PNAE/SEAP. Plano Nacional de Extensão Pesqueira e Aquícola. Brasília: 2008.

Polette, M.; Rebouças, G. N.; Filardi, A. C. L.; Vieria, P. F. Rumo à Gestão Integrada e Participativa de Zonas Costeiras no Brasil: Percepções da Comunidade Científica e do Terceiro Setor. Gestão Costeira Integrada, 5, 43-48, 2006. Disponível em: http://www.aprh.pt/rgci/pdf/RGCI_5.pdf

Ramires, M.; Molina, S. M. G.; Hanazaki, N. Etnoecologia Caiçara: o conhecimento dos pescadores artesanais sobre os aspectos ecológicos da pesca. Biotemas, 20(1), 101-113, 2007.

Ruddle, K. Systems of knowledge: dialogue, relationships and process. In: Begossi, A and Hens, L.. (Ed.). Environment, development and sustainability: a multidisciplinary approach to the theory and practice of sustainable development. Kluwer Academic Publishers, 2 v., n. 3/4, 2000.

Santos, A. Teorias e Método Pedagógico sob a Ótica do Pensamento Compllexo. In: Libâneo, J. C.; Santos, A. Educação na Era do Conhecimento em Rede e Transdisciplinaridade. Campinas: Editora Alínea, 2009.

Thiollent, M.; Branco, A.; Guimarães, R.; Araújo Filho, T. Extensão Universitária - conceitos, métodos e práticas. Rio de Janeiro: SR5/UFRJ, 2003.

Varella, F; Thompson, E.; Rosch, T. The Embodied Mind Cognitive: science and human experience. Cambridge, MIT/ Press, 1992.

Vasconcellos, M.; Diegues; A. C. S. A.; Sales, R. R. Limites e possibilidades na gestão da pesca artesanal costeira. In: Costa, A. L. Nas Redes da Pesca Artesanal. Brasília: IBAMA - MMA, 2007.

Vieira, P. F. Gestão dos Recursos Comuns para o Ecodesenvolvimento. In: Vieira, P. F; Berkes, F; Seixas, C. S. Gestão integrada e participativa de recursos naturais: conceitos, métodos e experiências. Florianópolis: Secco/APED. 2005.

Yamamoto, T. Development of a Community-Based Fishery Management System in Japan. Marine Resource Economics, 10, 21-34, 1995. 